\title{
Genotypes and haplotypes of the VEGF gene and survival in locally advanced non-small cell lung cancer patients treated with chemoradiotherapy
}

\author{
Xiaoxiang Guan ${ }^{1 \dagger}$, Ming Yin ${ }^{1 \dagger}$, Qingyi Wei ${ }^{1 *}$, Hui Zhao ${ }^{1}$, Zhensheng Liu', Li-E Wang ${ }^{1}$, Xianglin Yuan², \\ Michael S O'Reilly ${ }^{2}$, Ritsuko Komaki ${ }^{2}$, Zhongxing Liao ${ }^{2}$
}

\begin{abstract}
Background: Vascular endothelial growth factor (VEGF) is a major mediator of angiogenesis involving in carcinogenesis, including lung cancer. We hypothesized that VEGF polymorphisms may affect survival outcomes among locally advanced non-small cell lung cancer (LA-NSCLC) patients.

Methods: We genotyped three potentially functional VEGF variants [-460 T > C (rs833061), -634 G > C (rs2010963), and +936 C > T (rs3025039)] and estimated haplotypes in 124 Caucasian patients with LA-NSCLC treated with definitive radiotherapy. We used Kaplan-Meier log-rank tests, and Cox proportional hazard models to evaluate the association between VEGF variants and overall survival (OS).

Results: Gender, Karnofsky's performance scores (KPS) and clinical stage seemed to influence the OS. The variant C genotypes were independently associated with significantly improved OS (CT+CC vs. T: adjusted hazard ratio $[\mathrm{HR}]=0.58$; 95\% confidence interval $[\mathrm{Cl}]=0.37-0.92, P=0.022$ ), compared with the VEGF $-460 \Pi$ genotype.

Conclusions: Our study suggests that VEGF $-460 \mathrm{C}$ genotypes may be associated with a better survival of LA-NSCLC patients after chemoradiotherapy. Large studies are needed to confirm our findings.
\end{abstract}

\section{Background}

Non-small cell lung cancer (NSCLC) accounts for 89\% of all lung cancer, and 30\% of NSCLC patients present with locally-advanced unresectable tumors (unresectable stage IIIa and IIIb) [1]. Radiotherapy combined with chemotherapy, either sequentially or concurrently, is the standard treatment regimen for these patients, which, however, have resulted in unsatisfactory prognosis, with a 5-year survival rate of about $10-15 \%$ [1], and a median survival time (MST) of 16-18 months [2,3]. There has been a persistent interest in search for readily accessible molecular markers that may provide therapeutic benefits by predicting clinical outcomes of these locally advanced NSCLC (LA-NSCLC) on an individual basis.

Angiogenesis is an essential process in the development, growth, and metastasis of malignant tumors

\footnotetext{
* Correspondence: qwei@mdanderson.org

+ Contributed equally

'Department of Epidemiology, The University of Texas M. D. Anderson

Cancer Center, 1515 Holcombe Blvd, Houston, Texas 77030, USA

Full list of author information is available at the end of the article
}

including lung cancer [4]. Vascular endothelial growth factor (VEGF) is one of the most potent and predominant mediators of angiogenesis, which stimulate vascular endothelial cell growth, survival, and proliferation. Recent investigation has further revealed that VEGF acts as a mitogenic and survival signal for the tumor cell itself, indicating a broader range of tumor-promoting effects. Therefore, VEGF stands as a good candidate for prognostic biomarkers in cancer patients. Indeed, most tumors produce VEGF, whereas inhibition of the VEGF signaling significantly inhibits tumor growth in vivo [5]. In NSCLC, it has been found that a high expression of VEGF protein or mRNA was associated with increased tumor angiogenesis, early tumor relapse and reduced survival time [6-8]. A recent report further linked some functional $V E G F$ polymorphisms with prognosis of early stage (stage I and II) NSCLC, probably through regulation of VEGF expression [9]. However, LA-NSCLC accounts for a significant proportion of lung cancer, and 
it is not known if $V E G F$ polymorphisms are associated with prognosis within this particular population.

Previous studies primarily focused on three common functional single nucleotide polymorphisms of the VEGF gene, including the $-460 \mathrm{~T}>\mathrm{C},-634 \mathrm{G}>\mathrm{C}$ (also assigned as $+405 \mathrm{G}>\mathrm{C}$ ) and $+936 \mathrm{C}>\mathrm{T}$ (minor allele frequency $=0.422,0.431$ and 0.222 in Caucasians, respectively, according to the Hapmap database). The $-460 \mathrm{~T}>\mathrm{C}$ SNP is located in the promoter region and may influence the promoter activity [10]; the $-634 \mathrm{G}>$ C SNP lies within the 5'-untranslated region and may affect the transcriptional factor binding affinity [11]; the $+936 \mathrm{C}>\mathrm{T}$ SNP is located in the $3^{\prime}$-untranslated region and has been associated with lower VEGF plasma levels [12]. In the present study, we evaluated the association of these three potentially functional VEGF SNPs (i.e., $-460 \mathrm{~T}>\mathrm{C},-634 \mathrm{G}>\mathrm{C}$ [also assigned as $+405 \mathrm{G}>\mathrm{C}$ ] and $+936 \mathrm{C}>\mathrm{T}$ ) with overall survival (OS) of LANSCLC patients.

\section{Methods}

\section{Study populations}

Clinical data were derived from a large dataset of 576 NSCLC patients established at The University of Texas M. D. Anderson Cancer Center (Houston, TX), in which patients were recruited and histologically confirmed between Oct. 1998 and Nov. 2006. Details of this study population have been described previously [13]. Briefly, this analysis consisted of 124 Caucasian patients with stage IIIa or IIIb NSCLC according to the TNM staging system, a relatively homogenous group that was treated by chemoradiotherapy. Those patients who had surgical resection, or had been treated elsewhere before coming to M. D. Anderson were excluded from the analysis. The study protocol was approved by the M. D. Anderson Cancer Center institutional review board and informed consents were waived. We complied with Health Insurance Portability and Accountability Act (HIPAA) regulations.

\section{Genotyping}

Genomic DNA was extracted from the buffy coat fraction of each blood sample by using a Blood Mini Kit (Qiagen, Valencia, CA) according to the manufacturer's instructions. DNA purity and concentrations were determined by spectrophotometric measurement of absorbance at 260 and $280 \mathrm{~nm}$ by UV spectrophotometer. The selected three VEGF SNPs $(-460 \mathrm{~T}>\mathrm{C} / \mathrm{rs} 833061$, $-634 \mathrm{G}>\mathrm{C} / \mathrm{rs} 2010963$, and $+936 \mathrm{C}>\mathrm{T} / \mathrm{rs} 3025039)$ were genotyped using the polymerase chain reaction (PCR) -restriction fragment length polymorphism (RFLP) method. The PCR primers used for $-460 \mathrm{~T}>\mathrm{C}$, $-634 \mathrm{G}>\mathrm{C}$, and $+936 \mathrm{C}>\mathrm{T}$ polymorphisms were 5'-CTCTTTAGCCAGAGCCGGGG-3' (forward) and
5'-TGGCCTTCTCCCCGCTCCGAC-3' (reverse); 5'-CG ACGGCTTGGGGAGATTGC-3' (forward) and 5'-GGG CGGTGTCTGTCTGTCTG-3' (reverse); and 5'-AGGG TTCGGGAACCAGATC-3' (forward) and 5'-CTCGG TGATTTAGCAGCAAG-3' (reverse), respectively. The following PCR conditions were performed: one cycle at $95^{\circ} \mathrm{C}$ for $5 \mathrm{~min} ; 35$ cycles of $95^{\circ} \mathrm{C}$ for $30 \mathrm{~s}, 60^{\circ} \mathrm{C}$ for $30 \mathrm{~s}$, and $72^{\circ} \mathrm{C}$ for $45 \mathrm{~s}$; and a final extension at $72^{\circ} \mathrm{C}$ for 10 min. The PCR products were studied after digestion with BsaHI, BsmFI, and NlaIII restriction enzymes. Genotypes of these VEGF SNPs were determined as previously reported [14]. For the PCR-RFLP-based genotyping assay, two research assistants independently read the gel pictures, and the genotyping was repeated if there was a disagreement of the result. We selected $10 \%$ of the samples for replication, and the results were $100 \%$ concordant.

\section{Statistical analysis}

The two-sided $\chi^{2}$ and Student $t$ tests were performed to determine any statistically significant differences in the distributions of the $V E G F$ genotypes by the demographic variables and clinical features. We used the KaplanMeier estimates to evaluate OS among three genotype groups, and the log-rank test to test for equality of the survival distributions. We conducted univariate analysis and used multivariate Cox proportional hazard models to estimate the effect of each SNP on survival with or without other confounding factors. Haplotype frequencies and individual haplotypes were generated using SAS PROC HAPLOTYPE. The associations between haplotype and overall survival (OS) were determined using a dominant genetic model to preserve statistical power. All analyses were performed using SAS software (version 9.1; SAS Institute, Cary, NC).

\section{Results}

\section{Population characteristics}

Clinical and pathological characteristics of the patients included in current study are shown in Table 1. Among the 124 patients, there were 67 males (54\%) and 57 females (46\%), whose ages ranged from 35 to 88 years. There were 40 (32.3\%) adenocarcinoma, 38 (31.6\%) squamous cell carcinoma and 46 (37.1\%) large cell carcinoma. All patients received radiotherapy, delivered as 1.8 to 2 Gy per fraction once a day with a total median radiation dose of 66 Gy (ranging between 50 and 72 Gy). A number of 112 (90.3\%) patients also received platinum plus taxane or etoposide-based chemotherapy. At the end of follow-up, $92(74.2 \%)$ patients died, and the MST was 17 months (ranging between 1 and 97 months) in the overall study subjects.

To determine if there was any confounding factor influencing patients' death or survival time, we 
Table 1 Characteristics of the study population $(n=124)$ and overall survival

\begin{tabular}{|c|c|c|c|c|c|}
\hline Characteristics & No. of Patients (\%) & No. of Deaths (\%)* & $P^{\dagger}$ & MST (95\% Cl, month) & $P^{\ddagger}$ \\
\hline Age & & & 0.456 & & 0.468 \\
\hline$\leq 60$ years & $55(44.4)$ & $39(70.9)$ & & $21.0(13.0-32.0)$ & \\
\hline$>60$ years & $69(56.6)$ & $53(76.8)$ & & $18.0(13.0-26.0)$ & \\
\hline Gender & & & 0.175 & & 0.046 \\
\hline Female & $57(46.0)$ & $39(68.4)$ & & $26.0(17.0-38.0)$ & \\
\hline Male & $67(54.0)$ & $53(79.1)$ & & $17.0(12.0-22.0)$ & \\
\hline Smoke & & & 0.752 & & 0.679 \\
\hline Ever & $114(91.9)$ & $85(74.6)$ & & $20.0(16.0-26.0)$ & \\
\hline Never & $10(8.1)$ & $7(70.0)$ & & $16.0(11.0-18.0)$ & \\
\hline Pack -year & & & 0.542 & & 0.861 \\
\hline$\leq 40$ & $60(48.4)$ & $46(75.0)$ & & $19.0(14.0-29.0)$ & \\
\hline$>40$ & $64(51.6)$ & $46(73.0)$ & & $20.0(13.0-29.0)$ & \\
\hline Histology & & & 0.828 & & 0.632 \\
\hline Adenocarcinoma & $40(32.3)$ & $31(77.5)$ & & $20.0(17.0-31.0)$ & \\
\hline Squamous cell & $38(31.6)$ & $28(73.7)$ & & $16.0(12.0-25.0)$ & \\
\hline Others & $46(37.1)$ & $33(71.7)$ & & $24.0(13.0-36.0)$ & \\
\hline KPS & & & 0.175 & & 0.067 \\
\hline $90-100$ & $38(30.7)$ & $24(66.2)$ & & $22.0(16.0-39.0)$ & \\
\hline 80 & $67(54.0)$ & $53(79.1)$ & & $20.0(14.0-27.0)$ & \\
\hline$<80$ & $19(15.3)$ & $15(79.0)$ & & $13.0(8.0-29.0)$ & \\
\hline Stage & & & 0.057 & & 0.088 \\
\hline Illa & $52(41.9)$ & $34(65.4)$ & & $20.0(16.0-39.0)$ & \\
\hline IIlb & $72(58.1)$ & $58(80.6)$ & & $17.0(13.0-23.0)$ & \\
\hline Chemotherapy & & & 0.186 & & 0.766 \\
\hline Yes & $112(90.3)$ & $85(75.9)$ & & $20.0(16.0-26.0)$ & \\
\hline No & $12(9.7)$ & $7(58.3)$ & & $17.0(11.0-44.0)$ & \\
\hline Radiotherapy dose & & & 0.360 & & 0.857 \\
\hline$<70$ Gy & $59(47.6)$ & $46(78.0)$ & & $21.0(16.0-33.0)$ & \\
\hline$\geq 70$ Gy & $65(52.4)$ & $46(70.8)$ & & $17.0(12.0-24.0)$ & \\
\hline
\end{tabular}

Abbreviations: MST, median survival time.

* Percentage of deaths in each stratum.

${ }^{\dagger}$ Chi -square test for difference in the distribution of deaths.

₹ Log-rank test for survival time in the univariate analysis.

performed the chi-square test and univariate analysis of Log-rank test for the relationship of death number and OS with clinicopathologic characteristics. We did not find any significant difference in the death distribution by different clinicopathologic characteristics. However, gender seemed to be a confounding factor of OS (MST: 17 months of male vs. 26 months of female, $P=0.046$ ) (Figure 1A), whereas age, smoking status, pack-year, histology, application of chemotherapy, and radiation dose did not. Notably, Karnofsky's performance scores (KPS) and clinical stage showed a marginally significant association with $\mathrm{OS}(P=0.067$ and $P=0.088$ ) (Figure $1 \mathrm{~B}$ and $1 C$ ), suggesting they might be additional confounding factors required for control.

VEGF genotypes and NSCLC survival

The representative $\mathrm{PCR}$-based restriction analyses for the VEGF $-460 \mathrm{~T}>\mathrm{C},-634 \mathrm{G}>\mathrm{C}$, and $+936 \mathrm{C}>\mathrm{T}$ polymorphisms were shown in Figure 2. The genotype distributions of the three VEGF SNPs and the association with OS are summarized in Table 2. In all patient, the -460 CT genotype $(n=67)$ was associated with a significantly increased OS (crude hazard ratio [HR] = 0.60; 95\% confidence interval $[\mathrm{CI}], 0.37-0.95, P=0.031$ ), compared with the VEGF -460 TT genotype $(\mathrm{n}=33)$. After a multivariate adjustment with age, sex, smoking status, tumor histology, KPS score, tumor stage, history of chemotherapy, and radiation dose, the HR remained statistically significant (adjusted HR $=0.56 ; 95 \% \mathrm{CI}$, 0.34-0.90, $P=0.018$; Table 2). Although the homozygous $\mathrm{CC}$ genotype showed a tendency favoring increased OS, there was no statistical significance, probably because of a reduced detecting power resulting from small sample size $(n=24)$. Therefore, we combined the $\mathrm{CT}$ and CC genotypes for additional analysis. Under this dominant genetic model, the combined $-460 \mathrm{CT} / \mathrm{CC}$ 


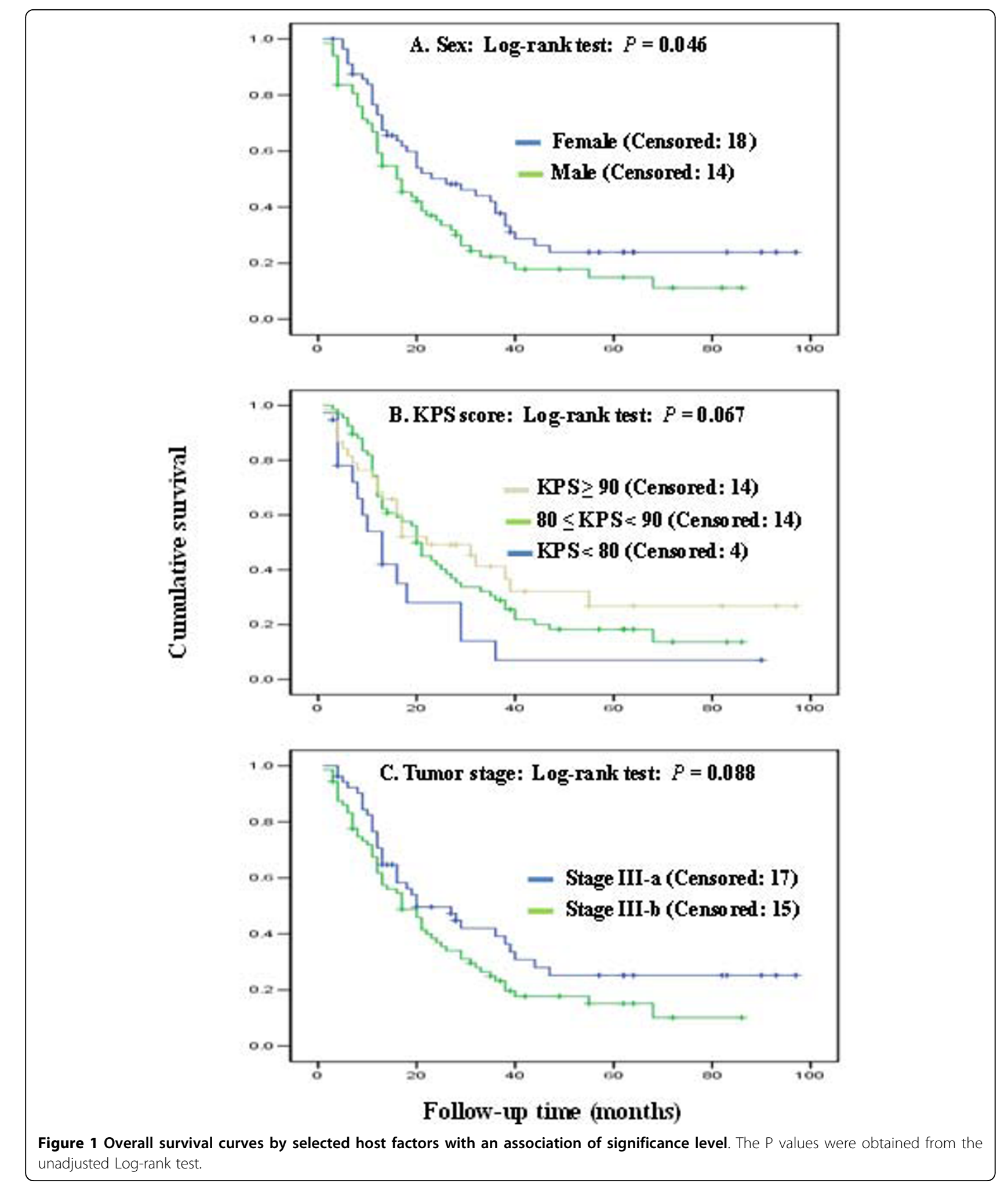




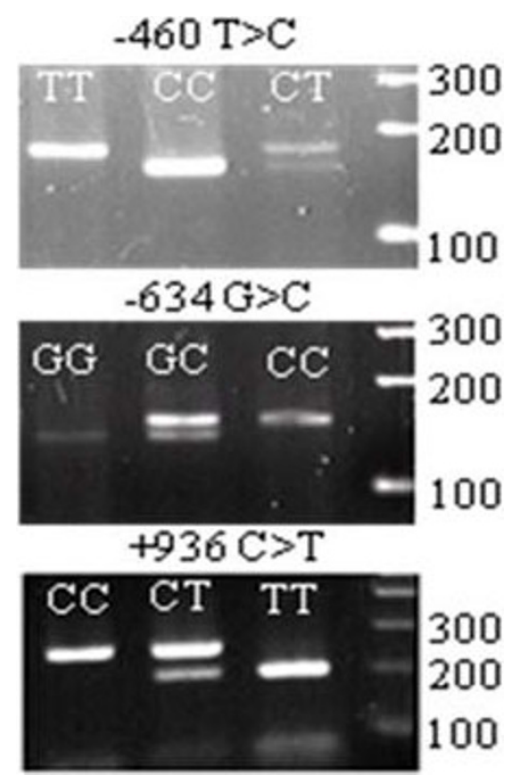

Figure 2 PCR-based restriction analysis of the VEGF SNPS shown on agarose electrophoresis.

variant genotypes $(\mathrm{n}=91)$ were associated significantly with improved OS (adjusted $\mathrm{HR}=0.58$; 95\% CI $=0.37$ $0.92, P=0.022$ ) (Figure $3 \mathrm{~A}$ ), compared with the $V E G F$ -460 TT genotype $(\mathrm{n}=33)$. For the other two $V E G F$ SNPs $-634 \mathrm{G}>\mathrm{C}$ and $+936 \mathrm{C}>\mathrm{T}$, we repeated the analyses but did not find any significant associations under either the additive model or dominant model (Table 2 and Figure $3 \mathrm{~B}$ and $3 \mathrm{C}$ ).
To determine if the influence of VEGF SNPs was substantially affected by tumor stage, we further made stratified analyses by separating the patients into two subgroups, stages IIIa and IIIb. We found that none of the three SNPs showed significant influence on OS, except for the CT genotype of VEGF -460 T > C SNP, which was marginally associated with increased OS in NSCLC patients of stage IIIb (adjusted HR $=0.56$; 95\% CI, $0.30-1.05, P=0.071$ and other data not shown).

\section{VEGF haplotypes and NSCLC survival}

We further explored the haplotypes to evaluate the combined effect of the three polymorphisms on NSCLC survivals. There were five haplotypes with frequencies $>$ $5 \%$ among all cases, and other less common haplotypes (frequencies $<5 \%$ ) were combined into one group. The five most common haplotypes in the patients were $-460 \mathrm{C} /-634 \mathrm{G} /+936 \mathrm{C}$ (C-G-C), T-C-C, T-G-C, T-C-T, and $\mathrm{C}-\mathrm{C}-\mathrm{C}$ with the respective frequencies of $38.8 \%$, $23.8 \%, 17.7 \%, 8.8 \%$ and $5.4 \%$, which were similar to those reported in the other Caucasian populations [15]. However, we did not find a significant impact on OS from the other haplotypes, compared to the most common C-G-C haplotype (data not shown).

\section{Discussion}

Several studies have reported the association between $V E G F$ polymorphisms and progress and survival of different cancers [16-19], but no study has investigated the association between the VEGF polymorphisms and LA-NSCLC patients' survival to date. To reduce

Table 2 Association between VEGF genotypes and overall survival

\begin{tabular}{|c|c|c|c|c|c|c|c|}
\hline Genotypes & Case No. & Deaths No. (\%)* & MST (95\% Cl, month) & Crude HR $(95 \% \mathrm{Cl})$ & $P^{\dagger}$ & Adjusted HR (95\% Cl) & $P^{\mp}$ \\
\hline \multicolumn{8}{|c|}{ VEGF -460T > C (rs833061) } \\
\hline$\pi$ & 33 & $28(84.9)$ & $16.0(11.0-25.0)$ & 1.00 & & 1.00 & \\
\hline $\mathrm{CT}$ & 67 & $47(70.2)$ & $21.0(17.0-32.0)$ & $0.60(0.37-0.95)$ & 0.031 & $0.56(0.34-0.90)$ & 0.018 \\
\hline $\mathrm{CC}$ & 24 & $17(70.8)$ & $27.0(10.0-36.0)$ & $0.75(0.41-1.37)$ & 0.347 & $0.67(0.36-1.26)$ & 0.212 \\
\hline $\mathrm{CT}+\mathrm{CC}$ & 91 & $64(70.3)$ & $21.0(17.0-31.0)$ & $0.63(0.40-0.99)$ & 0.043 & $0.58(0.37-0.92)$ & 0.022 \\
\hline \multicolumn{8}{|c|}{ VEGF -634G > C (rs2010963) } \\
\hline GG & 57 & $40(70.2)$ & $23.0(16.0-36.0)$ & 1.00 & & 1.00 & \\
\hline CG & 41 & $34(82.9)$ & $17.0(13.0-25.0)$ & $1.20(0.76-1.90)$ & 0.440 & $1.17(0.74-1.88)$ & 0.502 \\
\hline $\mathrm{CC}$ & 26 & $18(69.2)$ & $12.0(9.0-29.0)$ & $1.25(0.71-2.18)$ & 0.436 & $1.28(0.72-2.28)$ & 0.399 \\
\hline $\mathrm{CG}+\mathrm{CC}$ & 67 & $52(76.1)$ & $17.0(12.0-24.0)$ & $1.22(0.80-1.84)$ & 0.356 & $1.21(0.79-1.84)$ & 0.379 \\
\hline \multicolumn{8}{|c|}{$V E G F+936 C>T($ rs3025039) } \\
\hline $\mathrm{CC}$ & 92 & $68(73.9)$ & $21.0(16.0-29.0)$ & 1.00 & & 1.00 & \\
\hline $\mathrm{CT}$ & 30 & $22(73.3)$ & $17.0(11.0-29.0)$ & $1.08(0.67-1.75)$ & 0.742 & $1.00(0.60-1.66)$ & 0.992 \\
\hline$\pi$ & 2 & $2(100)$ & $14.5(9.0-20.0)$ & $2.14(0.52-8.80)$ & 0.291 & $1.95(0.46-8.29)$ & 0.367 \\
\hline $\mathrm{CT}+\mathrm{TT}$ & 32 & $24(75.0)$ & $17.0(11.0-28.0)$ & $1.13(0.71-1.80)$ & 0.606 & $1.05(0.65-1.71)$ & 0.839 \\
\hline
\end{tabular}

Abbreviation: MST, median survival time.

* Percentage of deaths in each stratum

† $P$ values were calculated using the log-rank test in the univariate analysis.

‡ $\mathrm{P}$ values were obtained from the Cox hazards model with adjustment for age, sex, smoking status, tumor histology, KPS score, tumor stage, application of chemotherapy and radiotherapy dose. 

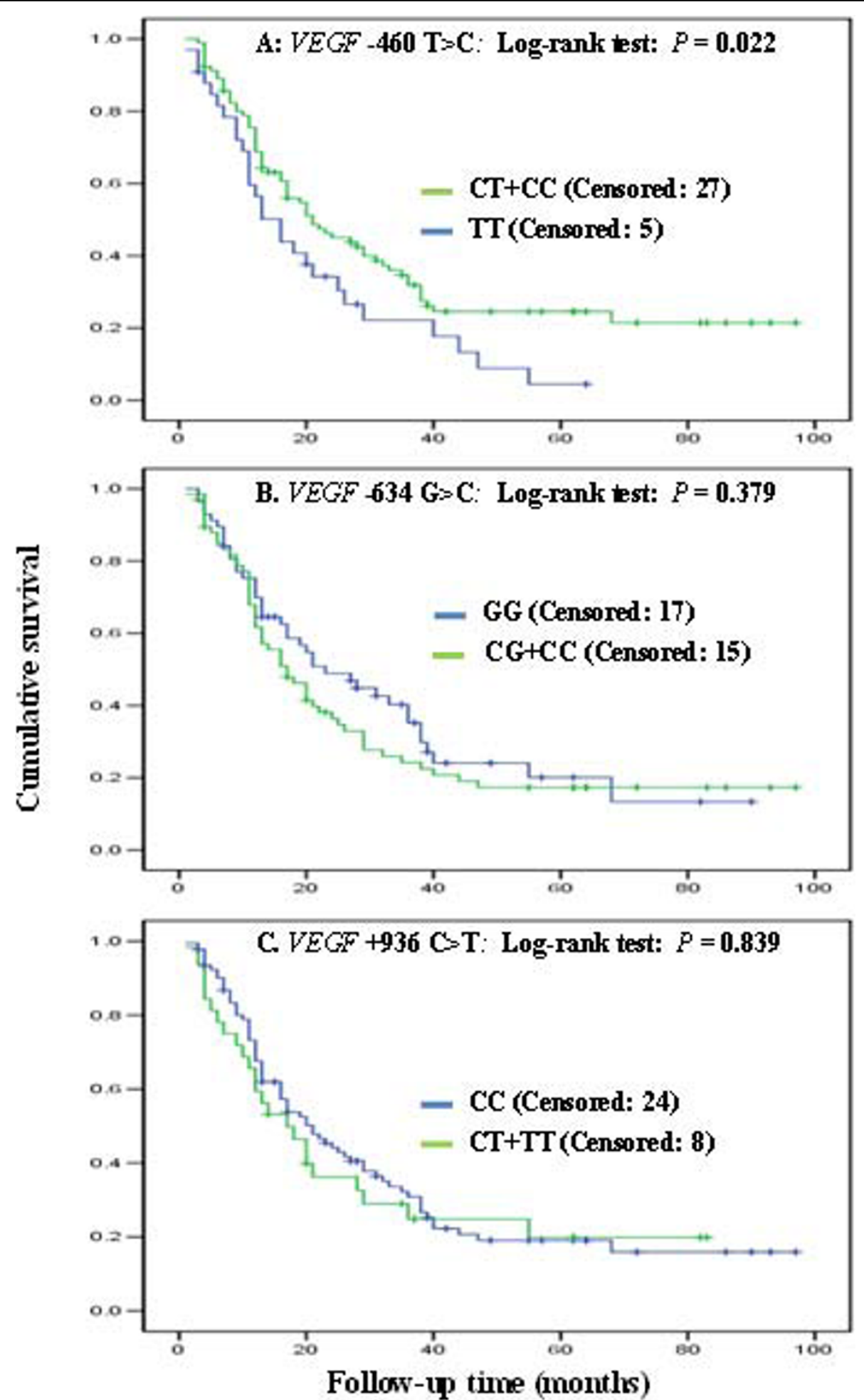

Figure 3 Overall survival curves by genotypes of VEGF gene. The P values were obtained from the Cox model with adjustment for age, sex, smoking status, tumor histology, KPS score, tumor stage, use of chemotherapy and radiotherapy dose. 
confounding effects of clinical parameters on the association, we limited our study subjects to a group of 124 Caucasian patients with homogenous stage IIIa and IIIb NSCLC, who received well-documented definitive chemoradiotherapy as previously described [13]. We found that the VEGF - $460 \mathrm{C}$ variant genotypes were associated with a significantly improved OS, compared with the VEGF -460 TT genotype.

To give a comprehensive view of the association between $V E G F$ genotypes and the prognosis of different cancer types, we summarized the published data in Table 3. Most of these studies confirmed an influence of $V E G F$ SNPs on the overall survival of cancer patients. However, these studies differed substantially in their conclusions. Even for the same VEGF SNP, different risk allele was reported. Different ethnic populations might be one rational reason for the inconsistent results. Another possible explanation may be that the effects of VEGF are tumor-specific. The interaction of different therapeutic strategies with $V E G F$ genotypes may also contribute to the diverse clinical outcomes. In NSCLC, the three studies (including ours) were not consistent in the VEGF risk alleles, suggesting that a further investigation was warranted. For example, Masago et al. reported an association between $-460 \mathrm{C}$ allele and a poorer survival of advanced NSCLC in Japanese patients [20], which was opposite to our findings in Caucasian patients. Numerous factors could have played a role in the ethnic discrepancy, including gene-gene interaction from different genetic background and gene-environmental interaction from different lifestyles. Even in the same ethnicity of Caucasians, the study by Heist et al. failed to find any significant association between $-460 \mathrm{C}$ allele and survival in 462 early-stage NSCLC patients, most of whom were surgically resected [9]. In that study, there were only 32 patients $(7 \%)$ receiving radiation and three patients $(0.6 \%)$ treated with chemotherapy. In contrast, the 124 LA-NSCLC patients of current study all received radiotherapy, and carriers of the $\mathrm{C}$ allele of $-460 \mathrm{~T}>\mathrm{C}$ polymorphism were found to benefit from radiotherapy. These findings, once validated in larger studies, will guide tailored therapeutics for individual patients.

It is not clear how the VEGF $-460 \mathrm{C}$ allele contributes to a better survival in LA-NSCLC patients. A previous in vitro study indicated that the $\mathrm{T}$ allele of the VEGF -460 $\mathrm{T}>\mathrm{C}$ polymorphism located in the promoter of the $V E G F$ gene was associated with a decreased $V E G F$ promoter activity [10]. Hence, the $V E G F-460 \mathrm{C}$ allele may be associated with an increased VEGF expression, which would promote tumor angiogenesis. However, the majority of NSCLC patients included in the current study received chemotherapy in addition to radiotherapy (112 out of 124). It is possible that the increased tumor vasculature may enhance radiotherapy efficacy through inhibiting tumor radioresistance from radiation-induced hypoxia, or facilitate the delivery of chemotherapeutic agents to the tumor site and may have led to enhanced synergistic effect with radiotherapy. Or, the VEGF -460 $\mathrm{C}$ allele has some additional unknown biological functions, besides regulation of mRNA expression. Further mechanistic studies are required to clarify this issue.

Table 3 Summary of the influence of VEGF SNPs on cancer OS

\begin{tabular}{|c|c|c|c|c|c|c|c|}
\hline $\begin{array}{l}\text { First } \\
\text { author }\end{array}$ & Year & Cancer & Country & Ethnicity & SNPs & No. & Risk allele \\
\hline $\begin{array}{l}\text { Guan } \\
\text { (Current) }\end{array}$ & 2010 & LA-NSCLC & USA & Caucasian & $-460 \mathrm{~T}>\mathrm{C},-634 \mathrm{G}>\mathrm{C}$, and $936 \mathrm{C}>\mathrm{T}$ & 124 & T for $-460 T>C$ \\
\hline $\begin{array}{l}\text { Formento } \\
\text { [23] }\end{array}$ & 2009 & Head\&neck & France & Caucasian & $-460 \mathrm{~T}>\mathrm{C},-634 \mathrm{G}>\mathrm{C}$, and $936 \mathrm{C}>\mathrm{T}$ & 49 & None \\
\hline $\begin{array}{l}\text { Masago } \\
{[20]}\end{array}$ & 2009 & $\begin{array}{l}\text { Advanced } \\
\text { NSCLC }\end{array}$ & Japan & Asian & $\begin{array}{c}-460 T>C,-1154 G>A,-2578 C>A \\
405 G>C, \text { and } 936 C>T\end{array}$ & 126 & $\begin{aligned} C \text { for }-460 T>C, & \text { A for }-1154 G>A, \text { and } A \text { for } \\
& -2578 C>A\end{aligned}$ \\
\hline $\begin{array}{l}\text { Dassoulas } \\
{[24]}\end{array}$ & 2009 & Colorectum & Greece & Caucasian & $\begin{array}{c}-460 T>C_{1}-634 G>C,-1154 G>A \\
-2578 C>A, \text { and } 936 C>T\end{array}$ & 312 & $\begin{array}{c}\text { T for }-460 \mathrm{~T}>\mathrm{C}, \mathrm{G} \text { for }-634 \mathrm{G}>\mathrm{C}, \mathrm{C} \text { for }-2578 \mathrm{C} \\
>\mathrm{A} \text {, and } \mathrm{C} \text { for } 936 \mathrm{C}>\mathrm{T}\end{array}$ \\
\hline $\begin{array}{l}\text { Bradbury } \\
{[25]}\end{array}$ & 2009 & Esophagus & Canada & Caucasian & $-460 \mathrm{~T}>\mathrm{C}, 405 \mathrm{G}>\mathrm{C}$, and $936 \mathrm{C}>\mathrm{T}$ & 361 & $C$ for $936 C>T$ \\
\hline Heist [9] & 2008 & $\begin{array}{l}\text { Early } \\
\text { NSCLC }\end{array}$ & USA & Caucasian & $-460 \mathrm{~T}>\mathrm{C}, 405 \mathrm{G}>\mathrm{C}$, and $936 \mathrm{C}>\mathrm{T}$ & 462 & G for $405 G>C$ and $C$ for $936 C>T$ \\
\hline Kim [16] & 2008 & Colorectum & Korea & Asian & $-634 \mathrm{G}>\mathrm{C},-2578 \mathrm{C}>\mathrm{A}$, and $936 \mathrm{C}>\mathrm{T}$ & 445 & G for $-634 G>C$ and $T$ for $936 C>T$ \\
\hline Kim $[26]$ & 2007 & Stomach & Korea & Asian & $\begin{array}{c}-116 \mathrm{G}>\mathrm{A},-460 \mathrm{~T}>\mathrm{C}, 405 \mathrm{G}>\mathrm{C}, \text { and } \\
936 \mathrm{C}>\mathrm{T}\end{array}$ & 503 & $C$ for $-460 T>C$ and $T$ for $936 C>T$ \\
\hline Kawai [27] & 2007 & Renal cell & Japan & Asian & $-634 G>C,-2578 C>A$, and $-1154 G>A$ & 213 & $C$ for $-2578 C>A$ \\
\hline Hefler [17] & 2007 & Ovarian & Austria & Caucasian & $-634 G>C,-1154 G>A$, and $-2578 C>A$ & 563 & None \\
\hline $\begin{array}{l}\text { Tzanakis } \\
{[28]}\end{array}$ & 2006 & Stomach & Greece & Caucasian & $\begin{aligned}-634 G>C, & -2578 C>A,-1154 G>A \\
& \text { and } 936 C>T\end{aligned}$ & 100 & $C$ for $-634 G>C$ \\
\hline Lu [19] & 2005 & Breast & China & Asian & $-460 \mathrm{~T}>\mathrm{C}, 405 \mathrm{G}>\mathrm{C}$, and $936 \mathrm{C}>\mathrm{T}$ & 1119 & $C$ for $-460 T>C$, and $G$ for $405 G>C$ \\
\hline
\end{tabular}


The strength of this study is that we included patients with stage IIIa and IIIb only, who received radiotherapy mostly in the range of 60-70 Gy with detailed OS data. However, there are several limitations. First, the study could not address the mechanism of how the VEGF polymorphisms influence the survival outcomes of lung cancer patients. Previous study demonstrated a good correlation between TC/CC genotypes of the VEGF -460 $\mathrm{T}>\mathrm{C}$ polymorphism and increased serum VEGF levels in colorectal cancer patients [21]. An increased serum VEGF expression was also observed in ovarian cancer patients carrying $-634 \mathrm{C}$ allele [22]. We are collecting related data to determine if there is such correlation between the VEGF polymorphisms and the VEGF protein levels in NSCLC patients. Secondly, we only included three common functional, promoter VEGF SNPs, which is far from comprehensive. Indeed, the $V E G F$ gene is highly polymorphic with at least 140 variants reported to date http://www.ncbi.nlm.nih.gov/SNP/. Some important functional SNPs may be missed or the observed association may result from genetic linkages with other untyped SNPs. Thirdly, our sample size is not big enough to allow evaluation of interactions between the studied polymorphisms and dose of radiation therapy. For the same reason, there appeared a wide confidence interval in our stratified analyses by tumor stage and the significance was lost due to the reduced statistical power. Therefore, a complete investigation of tagging SNPs in larger samples may be necessary in future studies.

\section{Conclusion}

In summary, we found that the $V E G F-460 \mathrm{C}$ allele may be associated with a better survival of LA-NSCLC patients treated with chemoradiotherapy. Future prospective studies with large sample sizes and better study designs are required to confirm our findings.

\section{Acknowledgements}

We thank Jiangong Niu, Jianzhong He and Kejing $\mathrm{Xu}$ and for their technical assistance. This study was in part supported by National Institutes of Health grants R01 ES11740 and R01 CA 131274 (to Q. W.) and P30 CA 16672 (to M. D. Anderson Cancer Center).

\section{Author details}

'Department of Epidemiology, The University of Texas M. D. Anderson Cancer Center, 1515 Holcombe Blvd, Houston, Texas 77030, USA. ${ }^{2}$ Department of Radiation Oncology, The University of Texas M. D. Anderson Cancer Center, 1515 Holcombe Blvd, Houston, Texas 77030, USA.

\section{Authors' contributions}

$X X G, Q Y W$, and $Z X L$ designed the study. XXG, ZSL and XLY performed the experiments. XXG, MY, and $H Z$ analyzed the data. XXG and MY wrote the manuscript. LEW, MSO, and RK coordinated the data and helped to revise the manuscript. All authors read and approved the final manuscript.

\section{Competing interests}

The authors declare that they have no competing interests.
Received: 5 April 2010 Accepted: 16 August 2010

Published: 16 August 2010

\section{References}

1. Yang P, Allen MS, Aubry MC, Wampfler JA, Marks RS, Edell ES, Thibodeau S, Adjei AA, Jett J, Deschamps C: Clinical features of 5,628 primary lung cancer patients: experience at Mayo Clinic from 1997 to 2003. Chest 2005, 128(1):452-462.

2. Cullen $M H$, Billingham $\amalg$, Woodroffe $C M$, Chetiyawardana $A D$, Gower $N H$, Joshi R, Ferry DR, Rudd RM, Spiro SG, Cook JE: Mitomycin, ifosfamide, and cisplatin in unresectable non-small-cell lung cancer: effects on survival and quality of life. J Clin Oncol 1999, 17(10):3188-3194.

3. Jeremic B, Shibamoto Y, Acimovic L, Djuric L: Randomized trial of hyperfractionated radiation therapy with or without concurrent chemotherapy for stage III non-small-cell lung cancer. J Clin Oncol 1995, 13(2):452-458.

4. Jain $L$, Vargo $C A$, Danesi $R$, Sissung $T M$, Price $D K$, Venzon $D$, Venitz J, Figg WD: The role of vascular endothelial growth factor SNPs as predictive and prognostic markers for major solid tumors. Mol Cancer Ther 2009, 8(9):2496-2508.

5. Langer C, Soria JC: The role of anti-epidermal growth factor receptor and anti-vascular endothelial growth factor therapies in the treatment of non-small-cell lung cancer. Clin Lung Cancer 11(2):82-90.

6. Yuan A, Yu CJ, Chen WJ, Lin FY, Kuo SH, Luh KT, Yang PC: Correlation of total VEGF mRNA and protein expression with histologic type, tumor angiogenesis, patient survival and timing of relapse in non-small-cell lung cancer. Int J Cancer 2000, 89(6):475-483.

7. Han H, Silverman JF, Santucci TS, Macherey RS, d'Amato TA, Tung MY, Weyant RJ, Landreneau RJ: Vascular endothelial growth factor expression in stage I non-small cell lung cancer correlates with neoangiogenesis and a poor prognosis. Ann Surg Oncol 2001, 8(1):72-79.

8. Shimanuki Y, Takahashi K, Cui R, Hori S, Takahashi F, Miyamoto H, Fukurchi Y: Role of serum vascular endothelial growth factor in the prediction of angiogenesis and prognosis for non-small cell lung cancer. Lung 2005, 183(1):29-42.

9. Heist RS, Zhai R, Liu G, Zhou W, Lin X, Su L, Asomaning K, Lynch TJ, Wain JC, Christiani DC: VEGF polymorphisms and survival in early-stage non-small-cell lung cancer. $J$ Clin Oncol 2008, 26(6):856-862.

10. Stevens A, Soden J, Brenchley PE, Ralph S, Ray DW: Haplotype analysis of the polymorphic human vascular endothelial growth factor gene promoter. Cancer Res 2003, 63(4):812-816.

11. Watson CJ, Webb NJ, Bottomley MJ, Brenchley PE: Identification of polymorphisms within the vascular endothelial growth factor (VEGF) gene: correlation with variation in VEGF protein production. Cytokine 2000, 12(8):1232-1235.

12. Renner W, Kotschan S, Hoffmann C, Obermayer-Pietsch B, Pilger E: A common $936 \mathrm{C} / \mathrm{T}$ mutation in the gene for vascular endothelial growth factor is associated with vascular endothelial growth factor plasma levels. J Vasc Res 2000, 37(6):443-448.

13. Yuan X, Liao Z, Liu Z, Wang LE, Tucker SL, Mao L, Wang XS, Martel M, Komaki R, Cox JD: Single nucleotide polymorphism at rs1982073:T869C of the TGFbeta 1 gene is associated with the risk of radiation pneumonitis in patients with non-small-cell lung cancer treated with definitive radiotherapy. J Clin Oncol 2009, 27(20):3370-3378.

14. Lee SJ, Lee SY, Jeon HS, Park SH, Jang JS, Lee GY, Son JW, Kim CH, Lee WK, Kam S: Vascular endothelial growth factor gene polymorphisms and risk of primary lung cancer. Cancer Epidemiol Biomarkers Prev 2005, 14(3):571-575.

15. Zhai R, Liu G, Zhou W, Su L, Heist RS, Lynch TJ, Wain JC, Asomaning K, Lin X, Christiani DC: Vascular endothelial growth factor genotypes, haplotypes, gender, and the risk of non-small cell lung cancer. Clin Cancer Res 2008, 14(2):612-617.

16. Kim JG, Chae YS, Sohn SK, Cho YY, Moon JH, Park JY, Jeon SW, Lee IT, Choi GS, Jun SH: Vascular endothelial growth factor gene polymorphisms associated with prognosis for patients with colorectal cancer. Clin Cancer Res 2008, 14(1):62-66.

17. Hefler LA, Mustea A, Konsgen D, Concin N, Tanner B, Strick R, Heinze G, Grimm C, Schuster E, Tempfer C: Vascular endothelial growth factor gene polymorphisms are associated with prognosis in ovarian cancer. Clin Cancer Res 2007, 13(3):898-901. 
18. Jin Q, Hemminki K, Enquist K, Lenner $P$, Grzybowska E, Klaes $R$, Henriksson R, Chen B, Pamula J, Pekala W: Vascular endothelial growth factor polymorphisms in relation to breast cancer development and prognosis. Clin Cancer Res 2005, 11(10):3647-3653.

19. Lu H, Shu XO, Cui Y, Kataoka N, Wen W, Cai Q, Ruan ZX, Gao YT, Zheng W: Association of genetic polymorphisms in the VEGF gene with breast cancer survival. Cancer Res 2005, 65(12):5015-5019.

20. Masago K, Fujita S, Kim YH, Hatachi Y, Fukuhara A, Nagai H, Irisa K, Ichikawa M, Mio T, Mishima M: Effect of vascular endothelial growth factor polymorphisms on survival in advanced-stage non-small-cell lung cancer. Cancer Sci 2009, 100(10):1917-1922.

21. Chen MH, Tzeng CH, Chen PM, Lin JK, Lin TC, Chen WS, Jiang JK, Wang HS, Wang WS: VEGF -460T - > C polymorphism and its association with VEGF expression and outcome to FOLFOX-4 treatment in patients with colorectal carcinoma. Pharmacogenomics J 2010.

22. Steffensen KD, Waldstrom M, Brandslund I, Jakobsen A: The relationship of VEGF polymorphisms with serum VEGF levels and progression-free survival in patients with epithelial ovarian cancer. Gynecol Oncol 117(1):109-116.

23. Formento JL, Etienne-Grimaldi $M C$, Francoual $M$, Pages $G$, Onesto $C$, Formento P, Chamorey E, Dassonville O, Poissonnet G, Milano G: Influence of the VEGF-A 936C > T germinal polymorphism on tumoral VEGF expression in head and neck cancer. Pharmacogenomics 2009, 10(8):1277-1283

24. Dassoulas K, Gazouli M, Rizos S, Theodoropoulos G, Christoni Z, Nikiteas N, Karakitsos P: Common polymorphisms in the vascular endothelial growth factor gene and colorectal cancer development, prognosis, and survival. Mol Carcinog 2009, 48(6):563-569.

25. Bradbury PA, Zhai R, Ma C, Xu W, Hopkins J, Kulke MJ, Asomaning K, Wang Z, Su L, Heist RS: Vascular endothelial growth factor polymorphisms and esophageal cancer prognosis. Clin Cancer Res 2009, 15(14):4680-4685.

26. Kim JG, Sohn SK, Chae YS, Cho YY, Bae HI, Yan G, Park JY, Lee MH, Chung HY, Yu W: Vascular endothelial growth factor gene polymorphisms associated with prognosis for patients with gastric cancer. Ann Oncol 2007, 18(6):1030-1036.

27. Kawai Y, Sakano S, Korenaga Y, Eguchi S, Naito K: Associations of single nucleotide polymorphisms in the vascular endothelial growth factor gene with the characteristics and prognosis of renal cell carcinomas. Eur Urol 2007, 52(4):1147-1155.

28. Tzanakis N, Gazouli M, Rallis G, Giannopoulos G, Papaconstantinou I, Theodoropoulos G, Pikoulis E, Tsigris C, Karakitsos P, Peros G: Vascular endothelial growth factor polymorphisms in gastric cancer development, prognosis, and survival. J Surg Oncol 2006, 94(7):624-630.

Pre-publication history

The pre-publication history for this paper can be accessed here: http://www.biomedcentral.com/1471-2407/10/431/prepub

doi:10.1186/1471-2407-10-431

Cite this article as: Guan et al:: Genotypes and haplotypes of the VEGF gene and survival in locally advanced non-small cell lung cancer patients treated with chemoradiotherapy. BMC Cancer 2010 10:431.

\section{Submit your next manuscript to BioMed Central and take full advantage of:}

- Convenient online submission

- Thorough peer review

- No space constraints or color figure charges

- Immediate publication on acceptance

- Inclusion in PubMed, CAS, Scopus and Google Scholar

- Research which is freely available for redistribution

Submit your manuscript at www.biomedcentral.com/submit
Biomed Central 